\title{
Self limiting postoperative hyperbilirubinemia after hepatectomy in a patient of Intrahepatic cholangiocarcinoma with Dubin-Johnson syndrome:
}

\section{A case report}

\author{
Nagarkar R.V., Roy S., Tondare A.A., Kulkarni N.C., \\ Suryavanshi S.P., Paleja N.P.
}

\begin{abstract}
Introduction: Dubin Johnson syndrome (DJS) is a benign disease of bilirubin metabolism, which causes only jaundice since birth, but there are no other symptoms or signs. DJS is so rare that its exact incidence in Indian population is not known. Incidence of intrahepatic cholangiocarcinoma (ICC) is around $3 \cdot 3 \%$. Occurrence of DJS simultaneous with hepatobiliary malignancies has been reported four times previously, predominantly in the Japanese population.
\end{abstract}

Nagarkar RV ${ }^{1}$, Roy S. ${ }^{2}$, Tondare A.A. ${ }^{3}$, Kulkarni N.C. ${ }^{4}$, Suryavanshi S.P. ${ }^{5}$, Paleja N.P. ${ }^{6}$

Affiliations: ${ }^{1} \mathrm{MS}$ (Gen Surg), DNB, MRCS (Edin), MNAMS, BSS (UK), Head of Dept., Surgical Oncology, Curie Manavata Cancer Center, Nashik, Maharashtra, India; ${ }^{2} \mathrm{MS}$ (Gen Surgery), Senior Consultant, Surgical Oncology, Curie Manavata Cancer Center, Nashik, Maharashtra, India; ${ }^{3}$ DNB (Gen Surgery), Surgery Registrar and Fellow Breast Surgery, Surgical Oncology, Curie Manavata Cancer Center, Nashik, Maharashtra, India; ${ }^{4} \mathrm{MD}$ (Anaesthesiaology), Head of Dept., Dept of Anaesthsiology, Curie Manavata Cancer Center, Nashik, Maharashtra, India; ${ }^{5} \mathrm{BHMS}, \mathrm{PGDCR}$, Managing Director, Manavata Clinical Research Institute, Curie Manavata Cancer Center, Nashik, Maharashtra, India; ${ }^{6}$ BAMS, PGDCR, Director, Manavata Clinical Research Institute, Curie Manavata Cancer Center, Nashik, Maharashtra, India.

Corresponding Author: Dr. Ashutosh Antappa Tondare, Curie Manavata Cancer Center, In front of Mahamarg Bus Stand, Mumbai Naka, Nashik, Maharashtra, Postal Code - 422004, India; Ph: +91 8552855111, Fax: +91 253 2594866; Email: dr.ashutosh.at@gmail.com

Received: 25 March 2015

Accepted: 23 May 2015

Published: 11 July 2015
There are no reports of such cases from Indian population. Also, in the reported cases the functional reserves of liver were complicated by presence of pre-existing cirrhosis of liver. There is no data suggesting the influence of concomitant DJS in a patient with liver cancers. Case Report: We present a case of 63-year-old (Indian) male who was diagnosed with DJS in early thirties and on routine health checkup was found to have space occupying lesion in liver. It turned out to be Intra hepatic cholangiocarcinoma on further workup. We state our experience in postoperative management, hyperbilirubinemia as well as further management of disease. Conclusion: Although it is not possible to predict the exact dynamics of DJS over ICC or vice versa, the outcomes of hepatectomy in such scenario are benign, self limiting and do not require any specific treatment.

Keywords: Dubin-Johnson syndrome, Intrahepatic Cholangiocarcinoma, Hepatectomy, Postoperative hyperbilirubinemia

\section{How to cite this article}

Nagarkar RV, Roy S, Tondare AA, Kulkarni NC, Suryavanshi SP, Paleja NP. Self limiting postoperative hyperbilirubinemia after hepatectomy in a patient of Intrahepatic cholangiocarcinoma with Dubin-Johnson syndrome: A case report. Int $J$ Hepatobiliary Pancreat Dis 2015;5:56-60.

Article ID: 100034IJHPDNV2015 
doi:10.5348/ijhpd-2015-34-CR

\section{INTRODUCTION}

(Few redundant facts have been omitted to shorten the introduction, and respective changes in the total number of references as well as the sequence has been done.)

Dubin-Johnson syndrome is a rare disorder of the bile transport causing mild conjugated hyperbilirubinemia, first described in 1954 as a benign and familial jaundice characterized by the deposition of characteristic black pigment in liver cells [1]. It is a genetically determined pathology of autosomal recessive inheritance.

Intrahepatic cholangiocarcinoma (ICC) is the second most common form of primary hepatic tumor accounting for $3.3 \%$ of all such cancers [2]. Etiology is varied and includes many rare disorders [3-11]. Five-year survival after operative resection ranges from $25-35 \%$ [12].

Patients of intrahepatic cholangiocarcinoma with jaundice usually have advanced locoregional disease and hence have a negative impact on the prognosis [13]. There is one previously reported case of concurrent occurrence of ICC in a patient with DJS from Czech population. So it is difficult to assess influence of mild conjugated hyperbilirubinemia over the outcome of surgery or the disease overall, in presence of such dual pathology.

\section{CASE REPORT}

A 63-year-old (Indian) male, who had jaundice all his life and who was diagnosed with Dubin-Johnson syndrome in his early thirties, presented with an incidental lesion in Liver. He was asymptomatic at presentation. The patient was an occasional alcoholic, non-smoker with no history suggestive of risk of acquiring hepatitis $\mathrm{B}$ or C. He had no medical or surgical co-morbidities. On examination he was icteric, but there were no other signs of liver cell failure. Liver was not palpable and no ascites. On an USG examination of abdomen, there was a lesion in the segment $\mathrm{V}$ and VI of liver, with features suggestive of neoplastic etiology. A PET CT scan of whole body showed, 7.5 $\times 5.5 \times 4.0 \mathrm{~cm}$ lesion with increased FDG uptake (Figures 1 and 2), in Segment IVB and V (SUV max 8.9). Lesion was closely abutting gallbladder medially. The blood investigations performed were negative for HIV, HbsAg, HCV. Liver function was normal except for conjugated hyperbilirubinemia (total $=6.5$, direct $=4.5$ ). Rest of his biochemical workup was within normal limits.

In view of a resectable lesion, non-cirrhotic liver, Child Pugh Group A and MELD score 13, a decision of wide resection of liver lesion was made. Intra-operative findings were that of no ascites or peritoneal/mesenteric deposits, $8 \times 6 \times 5 \mathrm{~cm}$ hard mass was present in the segment V and VI. There were two nodules adjacent to the primary. Liver was resected with a 2-cm margin. Cholecystectomy was done.
Postoperative course was essentially uneventful. There was no early or late complications. On third postoperative day bilirubin was 3.8 with direct component of 2.2, which gradually further decreased. (One month post-resection total=2.8, direct=2.). He was discharged on fourth postoperative day. Histopathological analysis showed poorly differentiated intrahepatic cholangiocarcinoma, with lymphovascular invasion. All resection margins were free. No nodal disease. Gallbladder was uninvolved. (T2bNoMo). He has been on adjuvant chemotherapy - single agent gemcitabine, which was in accordance with the current NCCN guidelines. After 2.5 months of surgery, he is asymptomatic and clinically stable, and is tolerating chemotherapy well.

\section{DISCUSSION}

Dubin-Johnson syndrome (DJS) is a rare disorder of the bile transport causing mild conjugated hyperbilirubinemia, a benign disorder requiring no treatment. It is a genetically determined pathology of autosomal recessive inheritance, thus favored by consanguineous marriages. The jaundice is stable most of the life except for exacerbations secondary to fatigue, emotional disturbances, physical exercise or infections, often followed by discrete hepatomegaly and choluria $[14,15]$. Dubin-Johnson syndrome has been described in all nationalities, ethnic backgrounds, and races. The

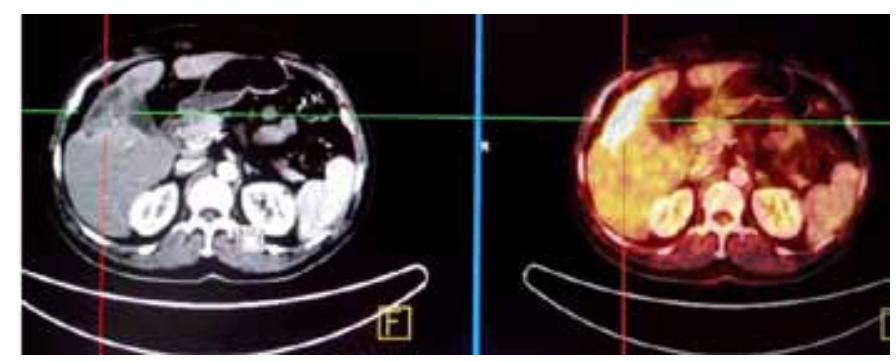

Figure 1: Computed tomography scan and PET CT image of abdomen in axial view showing the lesion in liver.

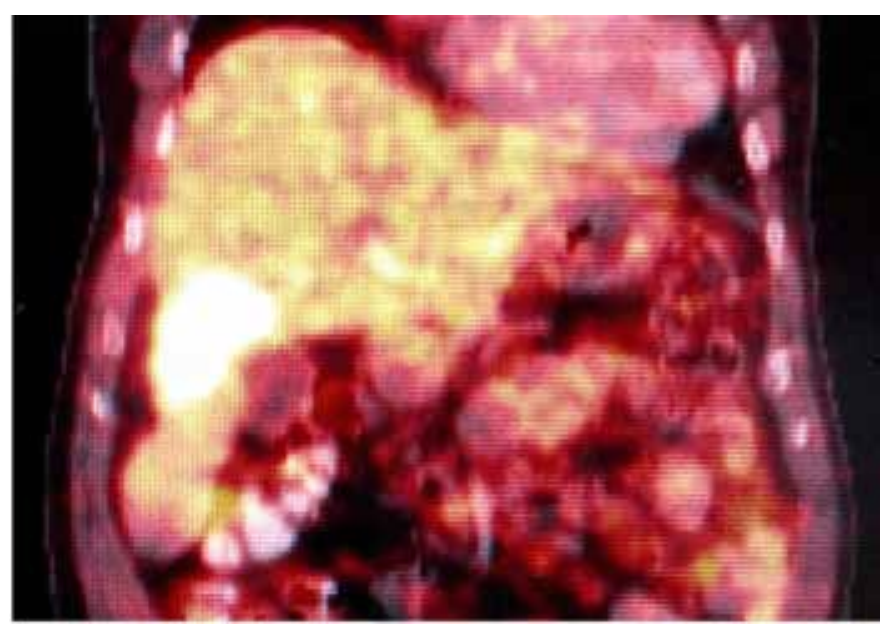

Figure 2: PET CT image of abdomen in coronal section showing the high FDG uptake in the lesion. 
highest recognized prevalence of the disease (1 case per 1300 population) is in Iranian Jews and is clustered in the same families [16]. The exact incidence of DJS in India is not known.

ICC is the second most common primary liver malignancy with a worldwide increase in incidence [17]. Surgical excision has been shown to be associated with increased survival in appropriately selected patients [18]. Alike most solid malignancies aim of intervention for ICC is $\mathrm{RO}$ resection ensuring the greatest chance of long-term recurrence free and overall survival. Also contributing to the survival are nodal disease and intrahepatic metastases. It has been shown that only surgical excision cannot prolong survival when disease has spread to lymph nodes as well as other parts of liver. Yet, surgery can still provide fair chance of survival if there are no intrahepatic metastases but nodal disease is present [19].

Our patient was diagnosed with DJS in young age and had jaundice as the only symptom, with no interference in his daily activities. He was incidentally found to have a neoplastic lesion with no distant spread, as evident by PET CT scan.

It has been found, that the patients with intrahepatic cholangiocarcinoma presenting or developing with jaundice, die within one year of diagnosis and are not the candidates for curative resection. The reason for such a clinical situation is one of the reasons viz., coexistence of tumor invading hepatic artery or portal vein, bilobar involvement of liver, extensive lymph node involvement or distant metastasis [13]. Only 30-45\% of patients are diagnosed before a distant metastasis or jaundice develops $[13,20]$. In our case, presence of jaundice in this patient of DJS with liver neoplasm could not be granted the marker of poor prognosis, indirect marker of inoperability or unresectability. On the contrary, our patient underwent a health checkup on his own, which probably gave a chance of finding this tumor before it could advance locally or metastasize.

Based on the results of PET CT, he was offered an attempt at curative resection. Also, in view of a poorly differentiated tumor and presence of lymphovascular emboli, we decided to offer him adjuvant gemcitabine based chemotherapy.

There are currently only four cases reported in the International literature, of patients suffering from DJS and classic hepatocellular carcinoma [21-24] and one patient reported with DJS and intrahepatic cholangiocarcinoma [25]. None of them are from Indian population. In all cases reported, patient had undergone a massive liver resection. Amongst the cases, Ueno et al. [23] and Shikada et al. [24] reported a post operative hyperbilirubinemia following liver resection. Ueno et $\mathrm{al}^{26}$, in 1998 reported difficulty in managing the post operative hyperbilirubinemia, requiring the usage of hemopurification, although the specific role of its usage has not been determined. But in 2004, Shikada et al. [24] reported that there was no requirement of such technique and bilirubin levels settled gradually. Similar experience was reported by Gamboa et al. [25] after liver resection for ICC. No other significant difference in the context of management of ICC was reported.

We report similar experience with postoperative hyperbilirubinemia without any specific therapy.

\section{CONCLUSION}

Dubin-Johnson syndrome (DJS) and intrahepatic cholangiocarcinoma are diseases of low incidence, and a combination of these two is extremely rare. The preoperative hyperbilirubinemia in intrahepatic cholangiocarcinoma might not be considered a marker for poor prognosis in presence of DJS. Post operative hyperbilirubinemia, appears to be a self limiting problem, but may depend upon preoperative liver reserves and amount of liver resected and /or functional reserve of the remaining liver.

$* * * * * * * * *$

\section{Author Contributions}

Nagarkar R.V. - Substantial contributions to conception and design, Analysis and interpretation of data, Revising it critically for important intellectual content, Final approval of the version to be published

Roy S. - Analysis and interpretation of data, Critical revision of the article, Final approval of the version to be published

Tondare A.A. - Substantial contributions to conception and design, Acquisition of data, Analysis andinterpretation of data, Drafting the article, Critical revision of the article, Final approval of the version to be published

Kulkarni N.C.- Acquisition of data, Revising it critically for important intellectual content, Final approval of the version to be published

Suryavanshi S.P.- Acquisition of data, Analysis of data, Drafting the article, Revising it critically for important intellectual content, Final approval of the version to be published

Paleja N.P. - Acquisition of data, Analysis and interpretation of data, Drafting the article, Critical revision of the article, Final approval of the version to be published

\section{Guarantor}

The corresponding author is the guarantor of submission.

\section{Conflict of Interest}

Authors declare no conflict of interest.

\section{Copyright}

(C) 2015 Nagarkar R.V. et al. This article is distributed under the terms of Creative Commons Attribution License which permits unrestricted use, distribution and reproduction in any medium provided the original 
author(s) and original publisher are properly credited. Please see the copyright policy on the journal website for more information.

\section{REFERENCES}

1. Dubin IN, Johnson FB. Chronic idiopathic jaundice with unidentified pigment in liver cells; a new clinicopathologic entity with a report of 12 cases. Medicine (Baltimore) 1954 Sep;33(3):155-97.

2. Liu RQ, Shen SJ, Hu XF, Liu J, Chen LJ, Li XY. Prognosis of the intrahepatic cholangiocarcinoma after resection: hepatitis $\mathrm{B}$ virus infection and adjuvant chemotherapy are favorable prognosis factors. Cancer Cell Int 2013 Oct 18;13(1):99.

3. Burak K, Angulo P, Pasha TM, Egan K, Petz J, Lindor $\mathrm{KD}$. Incidence and risk factors for cholangiocarcinoma in primary sclerosing cholangitis. Am J Gastroenterol 2004 Mar;99(3):523-6.

4. Bergquist A, Ekbom A, Olsson R, et al. Hepatic and extrahepatic malignancies in primary sclerosing cholangitis. J Hepatol 2002 Mar;36(3):321-7.

5. Watanapa P, Watanapa WB. Liver fluke-associated cholangiocarcinoma. Br J Surg 2002 Aug;89(8):96270 .

6. Kubo S, Kinoshita H, Hirohashi K, Hamba H. Hepatolithiasis associated with cholangiocarcinoma. World J Surg 1995 Jul-Aug;19(4):637-41.

7. Lesurtel M, Regimbeau JM, Farges O, Colombat M, Sauvanet A, Belghiti J. Intrahepatic cholangiocarcinoma and hepatolithiasis: an unusual association in Western countries. Eur J Gastroenterol Hepatol 2002 Sep;14(9):1025-7.

8. Su CH, Shyr YM, Lui WY, P'Eng FK. Hepatolithiasis associated with cholangiocarcinoma. Br J Surg 1997 Jul;84(7):969-73.

9. Chapman RW. Risk factors for biliary tract carcinogenesis. Ann Oncol 1999;10 Suppl 4:308-11.

10. Lipsett PA, Pitt HA, Colombani PM, Boitnott JK, Cameron JL. Choledochal cyst disease. A changing pattern of presentation. Ann Surg 1994 Nov;220(5):644-52.

11. Scott J, Shousha S, Thomas HC, Sherlock S. Bile duct carcinoma: a late complication of congenital hepatic fibrosis. Case report and review of literature. Am J Gastroenterol 1980 Feb;73(2):113-9.

12. Hyder O, Hatzaras I, Sotiropoulos GC, et al. Recurrence after operative management of intrahepatic cholangiocarcinoma. Surgery 2013 Jun;153(6):811-8.

13. Roayaie S, Guarrera JV, Ye MQ, et al. Aggressive surgical treatment of intrahepatic cholangiocarcinoma: predictors of outcomes. J Am Coll Surg 1998 Oct;187(4):365-72.

14. Haimi-Cohen Y, Amir J, Merlob P. Neonatal and infantile Dubin-Johnson syndrome. Pediatr Radiol 1998 Nov;28(11):900.

15. Kondo T, Yagi R, Kuchiba K. Letter: Dubin-Johnson syndrome in a neonate. N Engl J Med 1975 May 8;292(19):1028-9.

16. Zlotogora J. Hereditary disorders among Iranian Jews. Am J Med Genet 1995 Jul 31;58(1):32-7.

17. Endo I, Gonen M, Yopp AC, et al. Intrahepatic cholangiocarcinoma: rising frequency, improved survival, and determinants of outcome after resection. Ann Surg 2008 Jul;248(1):84-96.

18. Hanazaki K, Kajikawa S, Shimozawa $\mathrm{N}$, et al. Prognostic factors of intrahepatic cholangiocarcinoma after hepatic resection: univariate and multivariate analysis. Hepatogastroenterology 2002 MarApr;49(44):311-6.

19. Uenishi T, Kubo S, Yamazaki O, et al. Indications for surgical treatment of intrahepatic cholangiocarcinoma with lymph node metastases. J Hepatobiliary Pancreat Surg 2008;15(4):417-22.

20. Lieser MJ, Barry MK, Rowland C, Ilstrup DM, Nagorney DM. Surgical management of intrahepatic cholangiocarcinoma: a 31-year experience. J Hepatobiliary Pancreat Surg 1998;5(1):41-7.

21. Okamura J, Monden M, Horikawa S, et al. Hepatocellular carcinoma in a case of Dubin-Johnson syndrome treated successfully with right extended lobectomy. Jpn J Surg 1980 Dec;10(4):343-7.

22. Sakamoto A, Mori I, Kawai K, Tsuchiyama H. DubinJohnson syndrome associated with hepatocellular carcinoma--report of an autopsy case. Gan No Rinsho 1987 Sep;33(11):1361-7.

23. Ueno S, Tanabe G, Hanazono K, et al. Postoperative management following massive hepatectomy in a patient with Dubin-Johnson syndrome: report of a case. Surg Today 1998;28(12):1274-8.

24. Shikada Y, Matsumata T, Suehiro T, Sugimachi K. Hepatocellular carcinoma in a case of Dubin-Johnson syndrome treated successfully with a central bilateral segmentectomy. Hepatogastroenterology 2004 MayJun;51(57):833-6.

25. Gamboa C, Ricardo Yáñez M, Jorge Martínez C, et al. Hepatectomy for cholangiocarcinoma in one patient with Dubin Johnson syndrome. Rev Chil Cir [online]. 2009, vol.61, n.3, pp. 279-84. 
Access full text article on other devices

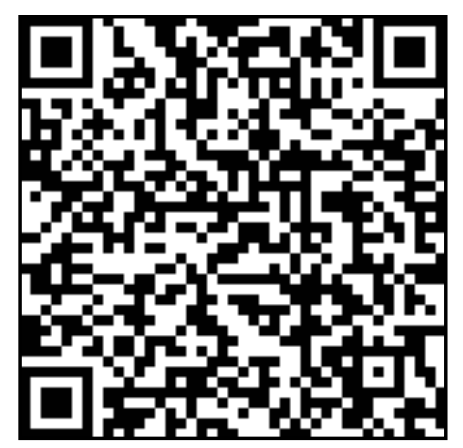

Access PDF of article on other devices

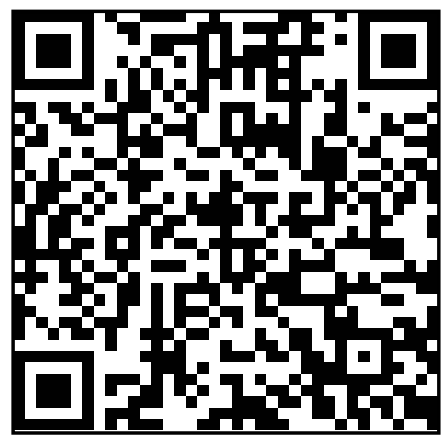

